\title{
FLOR PADILLA Y SUS NIÑAS MUÑECAS DE ENSUEÑO
}

Flor Padilla and her dream's doll girls

\author{
Oscar G. Pamo Reyna ${ }^{1}$
}

$\mathrm{F}$ lor de María Padilla Jáuregui nació en Lima el 17 de abril de 1980. Hija de Beltrán Padilla y Reyna Jáuregui, oriundos del distrito de Soras, provincia de Sucre, departamento de Ayacucho.

Terminando sus estudios secundarios ingresó a la Universidad Nacional Agraria La Molina, Lima, donde estudió la carrera de zootecnia, la cual culminó en el 2004. En el 2008, siguiendo sus sueños ingresó a la Escuela Nacional de Bellas Artes, Lima, donde estudió la carrera de artes plásticas con especialidad en pintura. Egresó en el 2013 y, desde entonces, se dedicó de lleno a trabajar en su propuesta artística.

Su interés por el arte nació desde muy temprana edad. Recuerda que desde que ingresó a las aulas, en el primer año de primaria, siempre estaba dibujando, le gustaba dibujar todo lo que llamara su atención, y siempre le gustaron los cursos donde tuviera que dibujar, y no siempre era el curso de arte. Por ejemplo, le gustaba el curso de biología donde siempre les enviaban a dibujar las células, disfrutando mucho, realmente, de esas tareas.

$\mathrm{Su}$ estilo fue madurando poco a poco, especialmente luego de culminar la carrera de artes plásticas. Considera que el hecho de estar

1 Profesor Principal del Departamento de Medicina, UPCH.

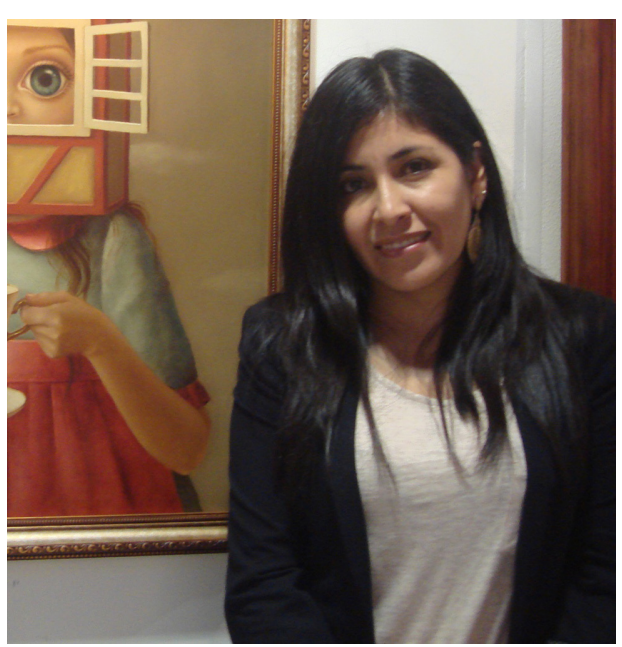

fuera de las aulas le dio la libertad de pintar libremente y de dejarse llevar por propios gustos estéticos.

Para Flor de María, su estilo, se podría decir, está dentro del surrealismo pop y, quizás más, dentro del realismo mágico, pues junta la técnica realista con temática fantástica. ${ }^{(1)}$ En su estilo influyeron artistas como Mark Ryden, pintor norteamericano, pionero del surrealismo pop, y también artistas como Nicoletta Ceccoli, entre otros. ${ }^{(2)(3)(4)}$

El surrealismo pop o arte lowbrow surgió a fines de la década de 1970 en Los Angeles, California. Fue un movimiento underground resultado de mezclar el cartoon, comic, anime, pop art, tatoo, etc.

2 Mark Ryden, pintor estadounidense nacido en 1963. Es considerado uno de los exponentes del movimiento lowbrow o surrealismo pop.

3 Nicoletta Ceccoli, artista italiana nacida en 1973 y que reside en San Marino.

4 La obra de Flor Padilla también nos recuerda a Margaret Doris Hawkins (Nashville, Tennesse, EE.UU., 1927), más conocida como Margaret Keane, cuyas pinturas de niños con "ojos grandes" se hicieran famosas en la década de 1960 y cuya historia fue recreada en la película "Big Eyes" de Tim Burton, a fines del 2014. 
Su vida artística compatibiliza perfectamente con su vida familiar, pues su pareja es también artista plástico y siempre están hablando de sus trabajos, ayudándose mutuamente $y$, sobre todo, creciendo juntos como artistas.

Flor de María aconseja a los jóvenes que desean dedicarse al arte que sigan sus sueños pero con los pies en la tierra y siempre trabajando, que el arte como toda profesión requiere de esfuerzo y dedicación, y recordarles que nada en esta vida es gratuito, "siempre tenemos que dar lo mejor de nosotros si queremos triunfar en lo que hacemos".

\section{DisTinCIONES:}

2015. Segunda mención honrosa en el concurso de pintura Arte en Libertad MAPFRE.

\section{EXPOSICIONES INDIVIDUALES:}

2013. Exposición Individual "Reminiscencias". Centro Cultural Ricardo Palma: Sala Raúl Porras Barrenechea. Lima

2017. Exposición Individual "Magical Dreams". Sala de exposiciones del Club de Regatas. Chorrillos

\section{EXPOSICIONES COLECTIVAS}

2012. Exposición Colectiva "Una mirada a lo nuevo". Galería Índigo.

2012. Exposición Colectiva "Visiones Generacionales". Museo Metropolitano de Lima.

2013. Exposición Colectiva "95 Aniversario de la ENSABAP". Centro Cultural Bellas Artes. 2014. Exposición de Egresados de Bellas Artes "Punto de Fuga". Casa Castilla.

2014. Exposición Colectiva "Dos mil Ocho". Centro Cultural Peruano Japonés.

2015. Exposición Colectiva “Desde mi Luna2». Fondo de Cultura Económica.

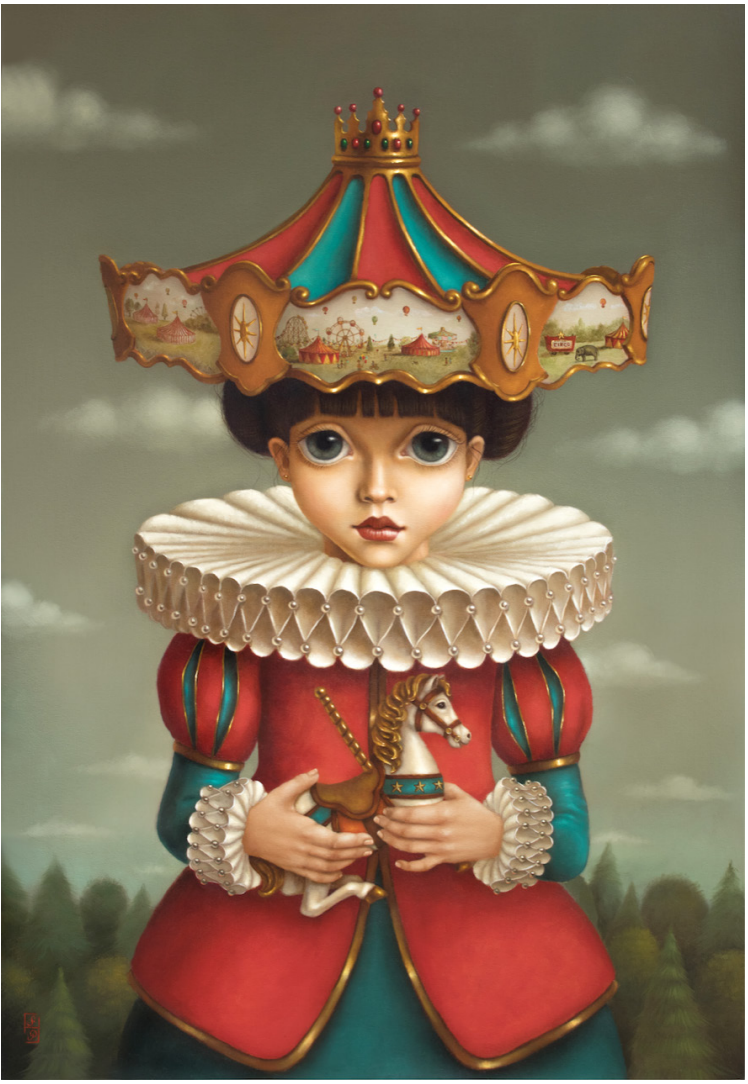

CARroussel OF DREAMS

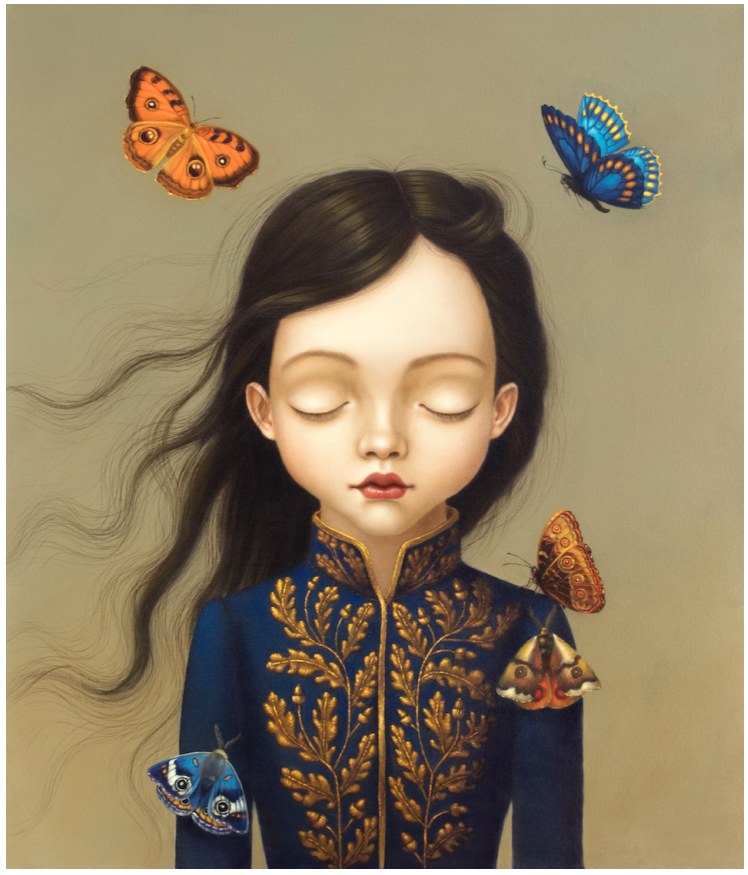

DREAMS OF FREEDOM 
2015.Exposición Colectiva «Mágico-Realismo». Centro Cultural Ricardo Palma, Miraflores. 2016. Exposición Colectiva «Únicas». Centro Cultural Chaves de la Rosa. Arequipa.

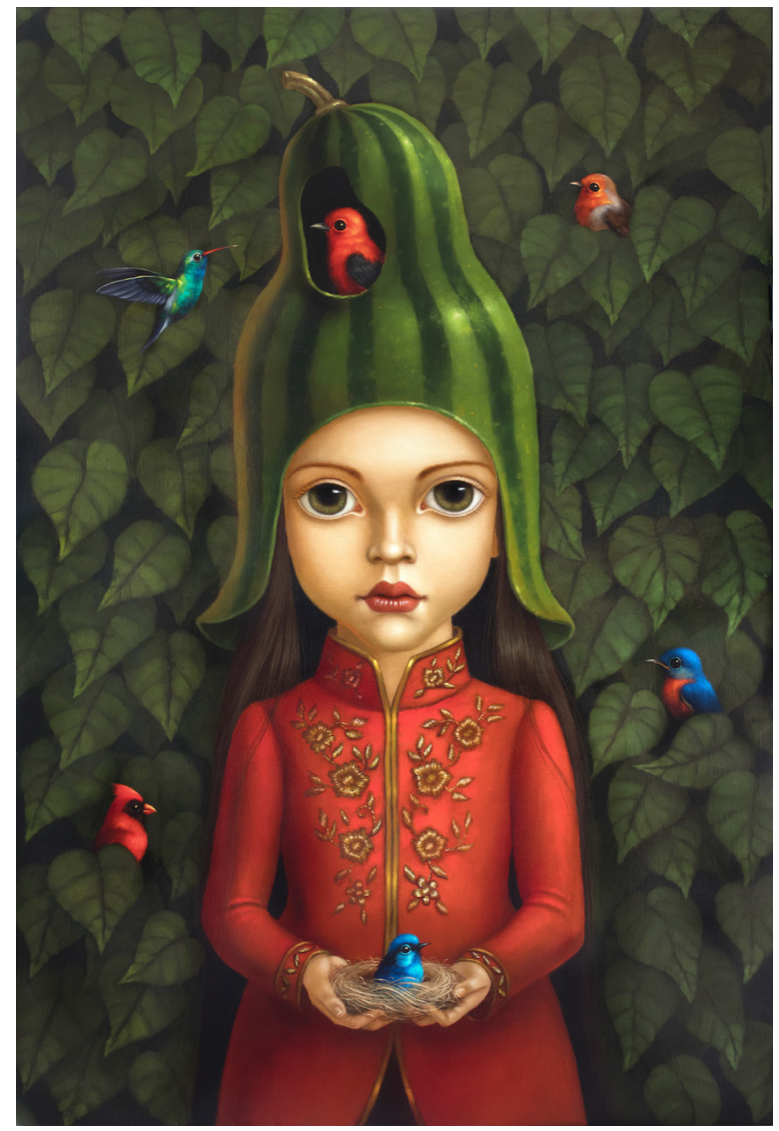

GUARDIAN OF BIRDS

Nota del Editor: Entrevistas realizadas entre el 17-012018 y el 05-02-2018.
2017. Exposición Colectiva “\# con mi retrato no te metas". Galería Juan Pardo Heeren-ICPNA.

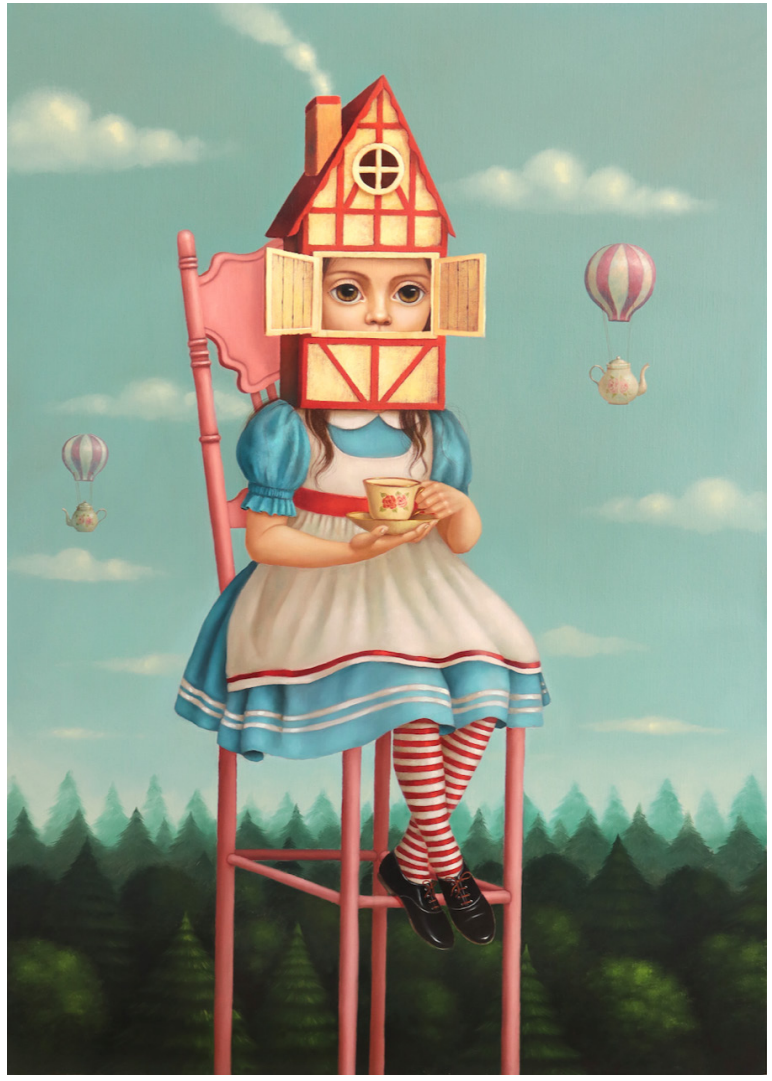

TEA TIME IN THE SKY 